Article

\title{
Silk Fibroin/Polyvinyl Pyrrolidone Interpenetrating Polymer Network Hydrogels
}

\author{
Dajiang Kuang ${ }^{1}$, Feng $\mathrm{Wu}^{1}{ }^{1}$, Zhuping Yin ${ }^{1}$, Tian Zhu ${ }^{1}$, Tieling Xing ${ }^{1}$, Subhas C. Kundu ${ }^{2}$ (D) \\ and Shenzhou $\mathrm{Lu}^{1, *}$ (i) \\ 1 National Engineering Laboratory for Modern Silk, College of Textile and Clothing Engineering, \\ Soochow University, Suzhou 215123, China; 20165215024@stu.suda.edu.cn (D.K.); \\ 20155215019@stu.suda.edu.cn (F.W.); 20154215016@stu.suda.edu.cn (Z.Y.); \\ 20134215013@stu.suda.edu.cn (T.Z.); xingtieling@suda.edu.cn (T.X.) \\ 2 3Bs Research Group, Headquarters of the European Institute of Excellence on Tissue Engineering and \\ Regenerative Medicine, University of Minho, AvePark, Barco, 4805-017 Guimaraes, Portugal; \\ kundu@hijli.iitkgp.ernet.in \\ * Correspondence: lushenzhou@suda.edu.cn; Tel.: +86-512-6706-1152
}

Received: 25 December 2017; Accepted: 4 February 2018; Published: 6 February 2018

\begin{abstract}
Silk fibroin hydrogel is an ideal model as biomaterial matrix due to its excellent biocompatibility and used in the field of medical polymer materials. Nevertheless, native fibroin hydrogels show poor transparency and resilience. To settle these drawbacks, an interpenetrating network (IPN) of hydrogels are synthesized with changing ratios of silk fibroin/N-Vinyl-2pyrrolidonemixtures that crosslink by $\mathrm{H}_{2} \mathrm{O}_{2}$ and horseradish peroxidase. Interpenetrating polymer network structure can shorten the gel time and the pure fibroin solution gel time for more than a week. This is mainly due to conformation from the random coil to the $\beta$-sheet structure changes of fibroin. Moreover, the light transmittance of IPN hydrogel can be as high as more than $97 \%$ and maintain a level of $90 \%$ within a week. The hydrogel, which mainly consists of random coil, the apertures inside can be up to $200 \mu \mathrm{m}$. Elastic modulus increases during the process of gelation. The gel has nearly $95 \%$ resilience under the compression of $70 \%$ eventually, which is much higher than native fibroin gel. The results suggest that the present IPN hydrogels have excellent mechanical properties and excellent transparency.
\end{abstract}

Keywords: silk fibroin; PVP; interpenetrating polymer network; hydrogel; protein biopolymer

\section{Introduction}

Hydrogels are of special soft and wet material with a three-dimensional network structure and high water content, the interior presents a porous, water-dispersed system, a certain strength and soft nature. They can be prepared by physical and chemical crosslinking [1-3]. Due to their porous structure, good biocompatibility and mechanical properties, the hydrogels are used as cell culture, drug delivery, biosensors and tissue engineering [4-6].

Silk fibroin (SF), derived from Bombyx mori cocoons, is a widely used and studied protein polymer for biomaterial applications [7]. Silk fibroin has remarkable mechanical properties when formed into different materials, which demonstrate biocompatibility [8-10]. It can be processed into different kinds of materials under different conditions, mainly including solution, film, microsphere, gel, filament, nanotube and scaffold [11-15]. Silk hydrogels are widely used as artificial skin, drug delivery carriers, microneedle systems and, biological sensors and tissue repairing [1,13,16-18]. Previous studies find that the hydrogel formation and sol-gel transition of the hydrogels depend on the protein concentration, temperature and $\mathrm{pH}$ [19]. In order to further improve the properties of fibroin hydrogel, silk fibroin can be mixed with other various polymers or macromolecules, such as chitosan, polyvinyl alcohol, 
hyaluronic acid, sodium alginate, gelatin and others [16,20-22]. The major drawbacks of these silk fibroin hydrogels are poor mechanical strength and bad biomedical applications $[1,3,19]$.

To overcome this drawback, in this study silk hydrogels properties are improved upon by forming interpenetrating networks of silk blended with $\mathrm{N}$-Vinyl-2-pyrrolidone, IPN (Interpenetrating Polymer Network). The polymer composites can be fabricated by thoroughly mixing the two or more types of molecular chains $[23,24]$. The most important feature of IPN polymer network is the thermodynamically incompatible polymer can be mixed to form at least the kinetic stability of the composites properties of the material in order to achieve the performance between the complementary components [25]. At the same time, characteristics about IPN like special cell structure, interfacial interpenetration and biphasic continuous structural morphological make them in the performance or function to produce a special synergistic effect.

It is known that polymer of $N$-Vinyl-2-pyrrolidone (PVP) has excellent biocompatibility and inert nature. This makes them suitable for applications in medical and pharmacy, human metabolism. Besides, PVP holds outstanding hydrophilicity and lubricity, which make it suitable to composite with other hydrophobic polymer and then increase the mixing system's hydrophilicity. Hosaka et al. mix and crosslink polyurethane with PVP monomer to produce high strength PVP hydrogel film [26-29]. Polyvinylpyrrolidone is used extensively with synthetic polymers such as polyvinyl alcohol and methyl methacrylate to prepare composite hydrogels to improve performances [30-32].

In this report, keeping in mind the past work and based on the excellent biosafety of hydrogel, we fabricate silk fibroin and $\mathrm{N}$-Vinyl-2-pyrrolidone interactive network hydrogel with high mechanical strength and elasticity as well as high transparency. This may be applied to contact lens and artificial vitreous materials.

\section{Materials and Methods}

\subsection{Materials}

The fresh silk cocoons from domestic mulberry silkworm Bombyx mori were purchased from Suzhou Sirui Biological Technology Co., Ltd., hydrogen Peroxide 30\% (Sinopharm Chemical Reagent Chemical Group Co., Ltd., Shanghai, China). Lithium bromide, N-vinyl-2-pyrrolidone (NVP), peroxidase from horseradish (HRP) (Aladdin Industrial Corporation, Shanghai, China). Anhydrous sodium carbonate, sodium bicarbonate, sodium chloride and all other chemicals (Sigma Chemicals Co., St. Louis, MO, USA,) used in this experiment were purchased.

\subsection{Preparation of Regenerated Silk Fibroin}

The silk cocoons $(80 \mathrm{~g})$ were cut into small pieces and degummed by boiling three times, in $4000 \mathrm{~mL}$ solution of $0.01 \mathrm{M} \mathrm{Na}_{2} \mathrm{CO}_{3} / \mathrm{NaHCO}_{3}$ in order to remove silk sericin [33]. The silk was then washed, air dried and dissolved in $9.3 \mathrm{M} \mathrm{LiBr}$ at $65^{\circ} \mathrm{C}$ for $1 \mathrm{~h}$ followed by dialysis against deionized water for 3 days at $4{ }^{\circ} \mathrm{C}$ using cellulose dialysis membrane (MWCO 8-10 kDa) with frequent water changes. The solution was finally centrifuged at $6000 \mathrm{rpm}$ for $15 \mathrm{~min}$ to remove impurities and precipitated matter [34].

\subsection{Preparation of IPN Hydrogels}

IPN hydrogels were prepared by free radical reaction. Briefly, silk fibroin (SF) protein concentration was adjusted to $40 \mathrm{mg} / \mathrm{mL}$ and NVP adjusted to $50 \mathrm{mg} / \mathrm{mL}$ with deionized water. Hydrogels were prepared by adding $2 \mathrm{~mL}$ of blended solution in centrifuge tube including SF/NVP (10:0, 9:1, 8:2, 7:3, 6:4, 5:5), $1 \mathrm{mM} \mathrm{H}_{2} \mathrm{O}_{2}$ and $10 \mathrm{unit} / \mathrm{mL}$ HRP. To this mixture, SF and NVP were added according to the blending ratios (Table 1). The solutions were allowed to gel in an incubator at $37^{\circ} \mathrm{C}$. The samples were finally removed from the mold, washed and immersed in deionized water for $24 \mathrm{~h}$ to remove unreacted monomers. 
Table 1. Indicates the content of each component in the mixed system.

\begin{tabular}{cccc}
\hline Composition & $\mathbf{4 0} \mathbf{~ m g / m L ~ S F ~}(\boldsymbol{\mu L})$ & $\mathbf{5 0 ~} \mathbf{~ g} / \mathbf{m L ~ N V P ~}(\boldsymbol{\mu L})$ & Deionized Water $(\boldsymbol{\mu L})$ \\
\hline SF/NVP: $10 / 0$ & 500 & 0 & 1298.6 .6 \\
SF/NVP: $9 / 1$ & 450 & 40 & 1308.6 \\
SF/NVP: $8 / 2$ & 400 & 80 & 1318.6 \\
SF/NVP: $7 / 3$ & 350 & 120 & 1328.6 \\
SF/NVP: $6 / 4$ & 300 & 160 & 1338.6 \\
SF/NVP: $5 / 5$ & 250 & 200 & 1348.6 \\
\hline
\end{tabular}

All components were added $\mathrm{H}_{2} \mathrm{O}_{2} 68 \mu \mathrm{L}(1 \mathrm{mg} / \mathrm{mL}), \mathrm{HRP} 133.4 \mu \mathrm{L}(0.25 \mathrm{mg} / \mathrm{mL})$. The final volume of the mixed solution was $2 \mathrm{~mL}$. The solid content was $10 \mathrm{mg} / \mathrm{mL}$, the temperature was $25^{\circ} \mathrm{C}$ and the relative humidity was $65 \%$.

\subsection{Morphology of PVP-SF IPN Hydrogels}

To characterize the internal structure of IPN, the hydrogel samples were observed using a scanning electron microscope (Hitachi TM3030, Hitachi Ltd., Tokyo, Japan). The samples were frozen by liquid nitrogen and then the sample were placed in a freezing dryer (Christ) and dried for $24 \mathrm{~h}$ to remove water. SEM images were acquired after gold sputtering at operating voltage of $15 \mathrm{kV}$ [35].

\subsection{FTIR Measurement}

All infrared spectra were recorded in the range of $600-1800 \mathrm{~cm}^{-1}$ using Thermo Nicolet 570 FTIR spectrometer (Nicolet Co., Madison, WI, USA). Each spectrum was acquired by accumulation of 16 scans with a resolution of $4 \mathrm{~cm}$. Background measurements were subtracted from sample readings.

\subsection{Wide-Angle X-ray Diffraction Measurement}

The crystalline state of Freezing-dried IPN hydrogels was tested by XRD. Test conditions: tube voltage $40 \mathrm{kV}$, tube current $35 \mathrm{~mA}$, scanning rate of $2^{\circ} / \mathrm{min}$ and using $\mathrm{Cu} \mathrm{K} \alpha$ rays. XRD patterns were recorded in the $2 \theta$ region from $10^{\circ}$ to $40^{\circ}$.

\subsection{Light Transmittance Characterization}

SF pure hydrogels and IPN hydrogels were equilibrated in 24-well plates and equilibrated in a $37^{\circ} \mathrm{C}$ incubator for $24 \mathrm{~h}$. The transmittance values were measured at 492, 550, $700 \mathrm{~nm}$ using a multifunctional microplate reader [36]. The thickness of the hydrogel in the experiment is controlled below $5 \mathrm{~mm}$ and the temperature is maintained at $37^{\circ} \mathrm{C}$.

\subsection{Mechanical Properties}

\subsubsection{The Compressive Stress-Strain Curve of IPN Gels}

In order to compare the compressive properties of hydrogels with different mass ratios, SF pure hydrogels and IPN hydrogels with different ratios were prepared. Cylindrical hydrogel samples with flat and parallel surfaces were prepared and the initial diameter and height of samples were $10 \pm 0.5 \mathrm{~mm}$ and $8 \pm 0.5 \mathrm{~mm}$ respectively. Compressive strength was determined by using Universal Testing Machine (Instron-3365, Instron Co., Norwood, MA, USA) at $25^{\circ}$ and $65 \%$ relative humidity. The test speed was set at $10 \mathrm{~mm} / \mathrm{min}$. All data were collected six samples $(n=6)$.

\subsubsection{Resilience Test of IPN Gels}

SF pure hydrogel and IPN hydrogel with different ratios were made into cylinders with a diameter of $10 \pm 0.5 \mathrm{~mm}$ and a height of $8 \pm 0.5 \mathrm{~mm}$. The samples were compressed twice and the compression displacement was $70 \%$ of the original height of the samples. The variation curve was analyzed in the system software and the parameter values are obtained and the variation law was analyzed [37]. Test conditions: control the lifting arm speed of $1 \mathrm{~mm} / \mathrm{s}$, the trigger force of $10 \mathrm{~g}$, the test used in the circular probe model $\mathrm{P} / 2$, detection accuracy $\geq 0.015 \%$. 


\subsection{Enzymatic Degradation of IPN Gels In Vitro}

IPN hydrogels were immersed in PBS (phosphate buffer saline) $\left(37^{\circ} \mathrm{C}, \mathrm{pH}\right.$ : 7.4) containing protease XIV (2 U/mL, Sigma-Aldrich, St. Louis, MO, USA) at a bath ratio of 1/100 (w/v). Hydrogels peptide content derived from enzymatic degradation was measured by sampling at designated time points, 4 parallel samples each group [38]. Percentage enzymatic IPN hydrogels degradation was calculated using Equation (1) mentioned above.

$$
\text { WeightRemain } \%=\frac{m_{2}}{m_{1}} \times 100 \%
$$

where $m_{1}$ and $m_{2}$ are the mass of hydrogels before and after immersion in PBS.

\section{Results}

\subsection{Preparation of IPN Hydrogels}

Interpenetrating network hydrogel were fabricated mixing solutions of silk fibroin with NVP solutions, $\mathrm{HRP}$ and $\mathrm{H}_{2} \mathrm{O}_{2}$. During this process, NVP was used to generate free radicals under the catalysis of initiator $\mathrm{H}_{2} \mathrm{O}_{2}$ and horseradish peroxidase (HRP), which initiated the polymerization of monomers to produce polyvinylpyrrolidone and reacted with silk fibroin macromolecule entanglement, ultimately formed the interpenetrating network (IPN) hydrogel (Scheme 1).

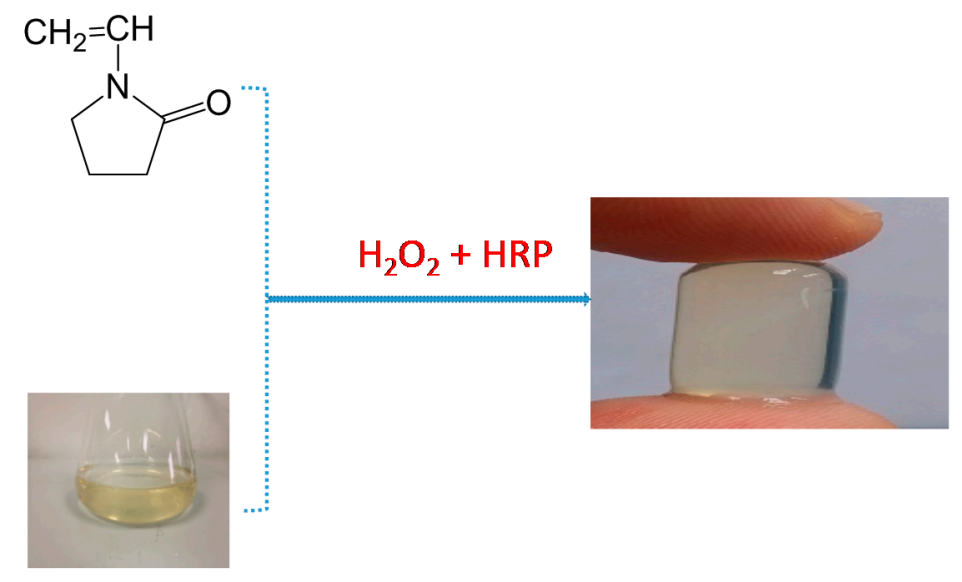

\section{Silk Fibroin}

Scheme 1. Formation of PVP-SF IPN hydrogel using $\mathrm{HRP}-\mathrm{H}_{2} \mathrm{O}_{2}$ system.

\subsection{Morphology of IPN Hydrogels}

The IPN hydrogels performed dense and uniform porous structures (SEM, Figure 1). The SEM images also revealed that regular pore structure with clear pores and high porosity within PVP-SF IPN hydrogels. The pore sizes ranged from 80 to $200 \mu \mathrm{m}$, which were much larger than the internal pore sizes of pure silk hydrogels. The larger pores allow for the efficient delivery of the water and nutrients inside the gel. This provides sufficient space and suitable environment for cell growth and proliferation. Decrease in silk fibroin content, the internal porosity of the hydrogel became larger and uniform. With the increase of NVP content, the conversion rate decreased. This would reduce the entanglement points of polymer and silk fibroin macromolecules. This results in the internal structure of the hydrogel loose and the pores became larger. 


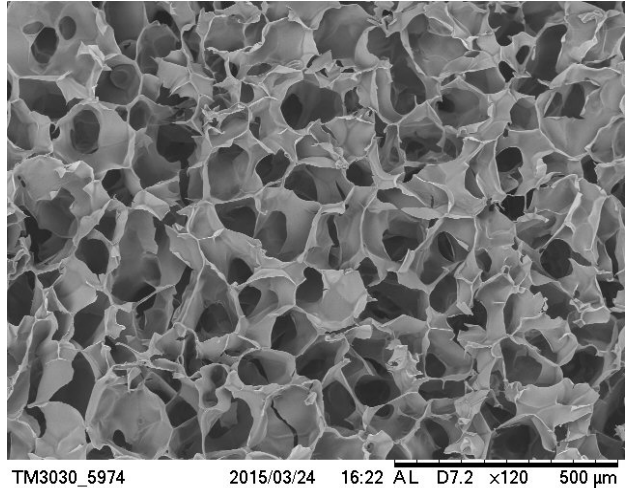

(A)

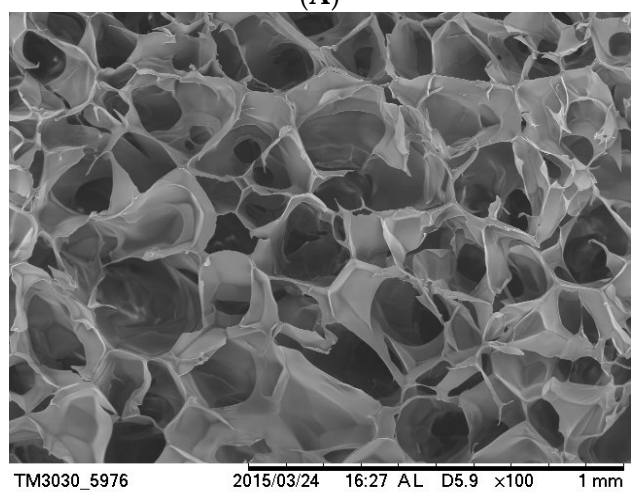

(C)

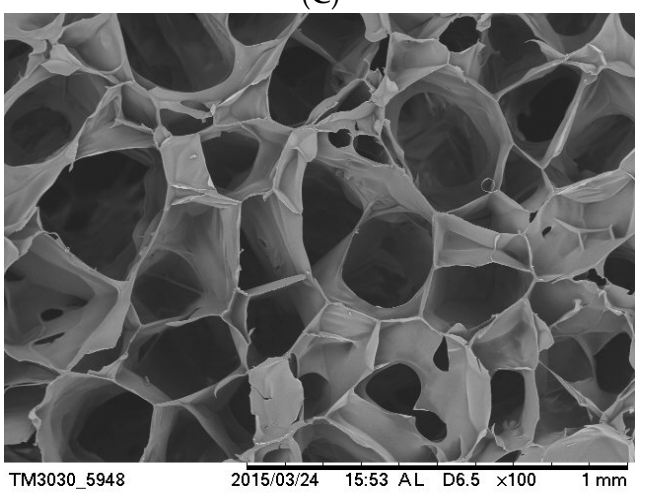

(E)

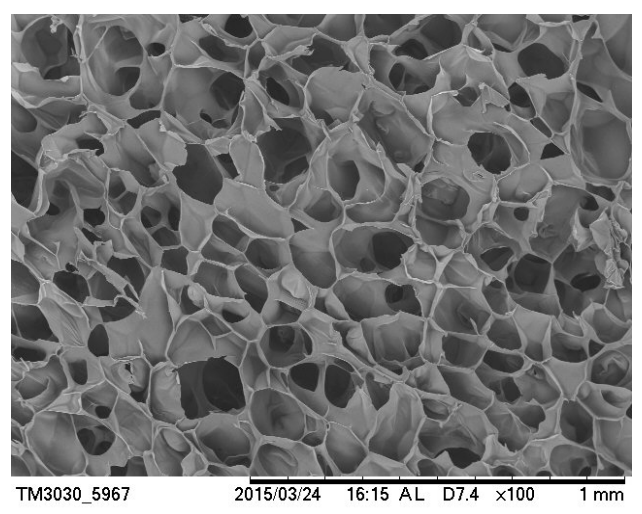

(B)

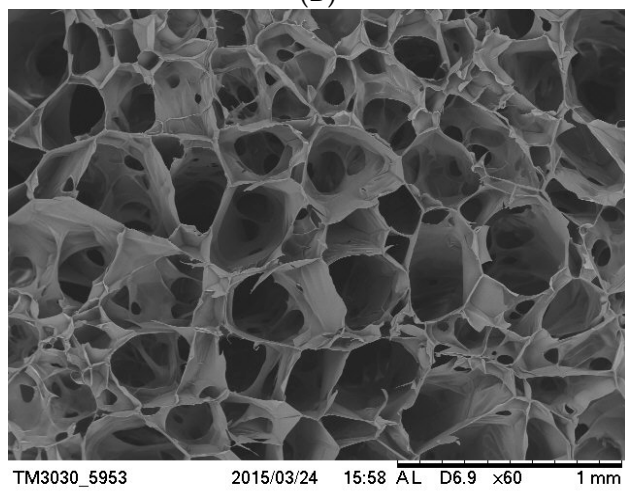

(D)

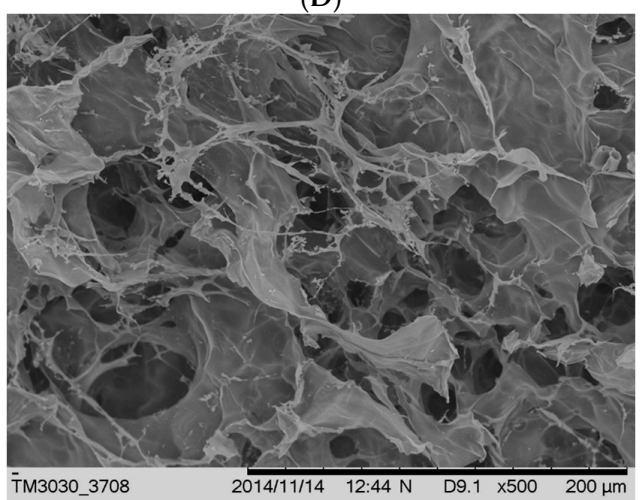

(F)

Figure 1. SEM images of cross-section morphology with different ratios of SF/NVP: (A) 90/10, (B) 80/20, (C) 70/30, (D) 60/40, (E) 50/50 and (F) pure SF hydrogel.

\subsection{Conformation and Aggregation Structure of Fibroin Hydrogels}

The FITR spectra of the freeze-dried IPN hydrogel and pure SF hydrogel are shown in Figure 2. There was no significant difference between different proportions of interpenetrating network hydrogels of the FITR spectra (Figure 2A). The pure SF hydrogel exhibits characteristic absorption peaks at 1233, 1532, $1635 \mathrm{~cm}^{-1}$ which are the characteristic peaks of the $\beta$-sheet structure [39]. SF/PVP IPN hydrogels had obvious absorption peaks at $1530,1630 \mathrm{~cm}^{-1}$ which are the characteristic peaks of random coil of SF [39]. The results indicate that the main structure of SF in IPN hydrogels is random coil.

Figure 2B shows the XRD diffraction curve of IPN hydrogel material. X-ray diffraction is an effective method for studying crystal materials and amorphous material structures [40]. There was no significant difference between the XRD diffraction curve of different proportions of interpenetrating network hydrogels (Figure 2B). It can be observed from the figure that the IPN hydrogel had a large 
bunted peak at $20^{\circ}$, which was characterized by a typical amorphous structure. That was consistent with the FTIR spectrum. Whereas the pure silk gel at $20.3^{\circ}$ and $24.3^{\circ}$ with a sharp absorption peak. This indicated that the pure silk fibroin had a certain crystal structure (Figure 2B).

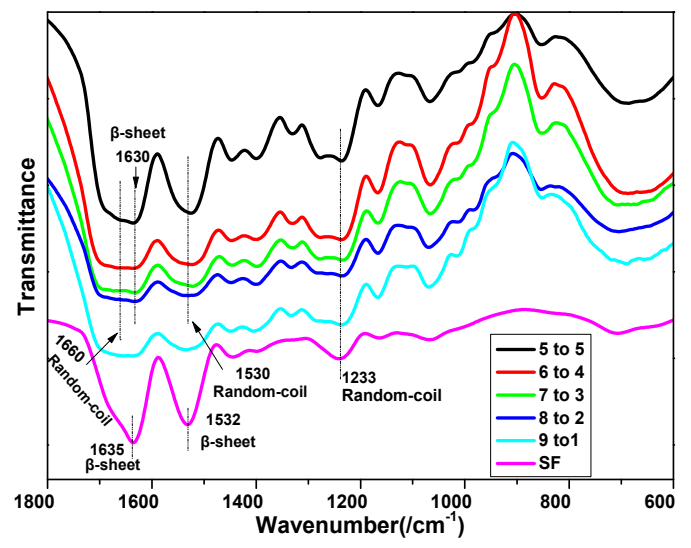

(A)

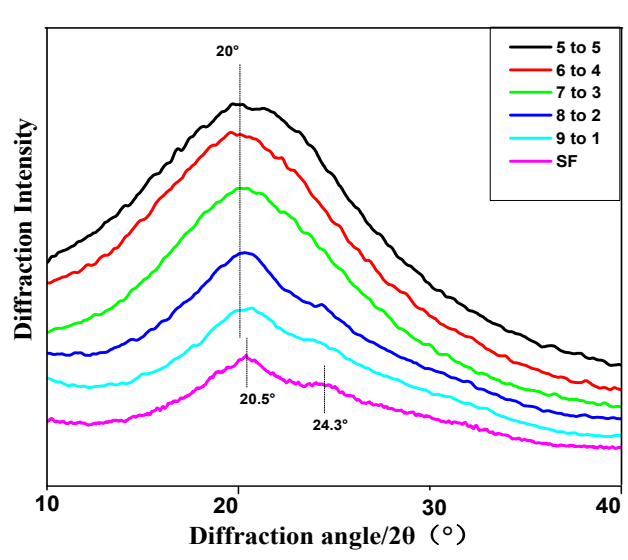

(B)

Figure 2. Structure of fibroin hydrogels. (A) FTIR; (B) X-ray diffraction. The solid content of hydrogel was $10 \mathrm{~g} / \mathrm{L}$.

\subsection{Compression Mechanical Properties}

In the stress-strain curve, both the hydrogel samples showed some nonlinear behaviors. With the increase of strain, the compressive stress on the material increased and the pure silk fibroin hydrogel appeared at about $50 \%$ compression compressive rupture phenomenon (Figure $3 \mathrm{~A}$ ). The IPN hydrogel material in the maximum compression up to $70 \%$ of the stress was still increased. The material remained intact and the material quickly rebound after the pressure was removed. The results showed that the internal structures of IPN hydrogel were regular, cross-linked closely, excellent compressive strength and resilience. IPN hydrogel significantly enhanced the compressive strength and compressive resilience of the hydrogel because of its macromolecule network entanglement.

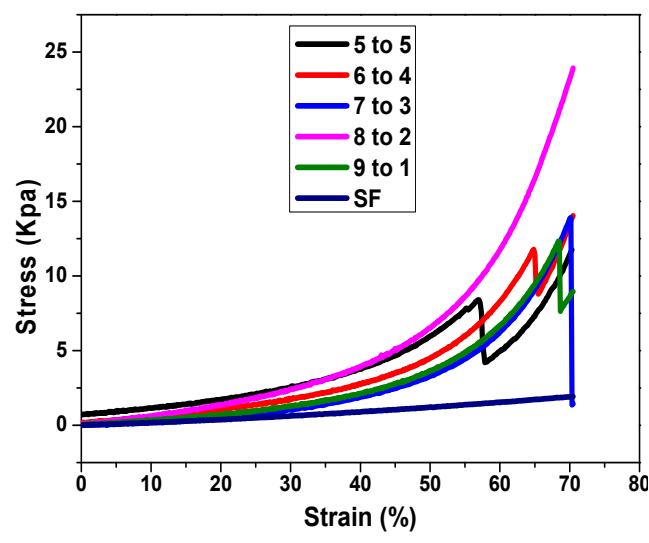

(A)

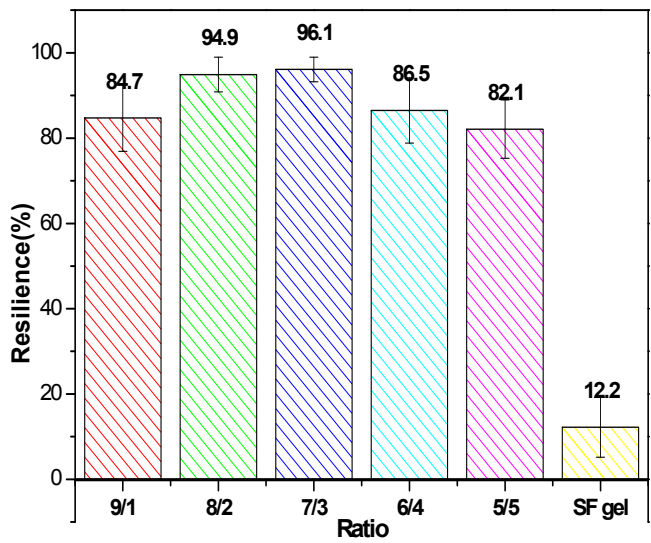

(B)

Figure 3. Compression mechanical properties. (A) Stress-strain curves of PVP-SF IPN hydrogels. (B) Stress resilience of PVP-SF IPN hydrogels. The solid content was $10 \mathrm{~g} / \mathrm{L}$, the temperature was $25^{\circ} \mathrm{C}$ and the relative humidity was $65 \%$.

The sample of IPN hydrogel was compressed by TPA (Test process analysis) test for consecutive compressions. Resilience is the ability of the sample to rebound during the first compression, 
which is the ratio of the elastic energy released by the sample upon return during the first compression cycle to the energy dissipated by the probe during compression. The sample of IPN hydrogel was compressed by TPA test for two consecutive compressions. IPN hydrogel materials have a high rebound rate of up to $95 \%$ resilience, compared with only about $12 \%$ of pure silk fibroin hydrogel. Due to the network interpenetrating structure within the material, the entanglement and the physical crosslink density of the molecular chain were greatly increased. The material underwent elastic deformation when being compressed without any damaged. A texture analyzer was used to measure and evaluated the mechanical differences between different ratios of PVP-SF IPN hydrogel and pure silk hydrogel. Notably, both the gel samples showed non-linear behavior. Stress of the hydrogel showed an increasing trend with an increase in strain. The compression fracture occurred when the pure silk gel was compressed by about $50 \%$. IPN hydrogel at the maximum compression up to $70 \%$ of the stress was still increased. The shape was complete and the rapid removal of hydrogel after the pressure rebound, the IPN hydrogel showed higher mechanical properties compared with the pure silk hydrogel. This significantly increased the compressive strength and compressive resilience of the hydrogel by virtue of the regular cross-linking of the internal structure of the macromolecule network. This is summarized in Figure 3A,B.

\subsection{Light Transmittance Characterization}

The contact lens material of contact optical system consists, corneal related part, contact lens and the formation of tears in the cornea [41]. The copolymer hydrogels are used in the application of corneal contact lens materials, which is required to have good light transmission. When light propagates through a polymeric material, it causes a material-valence electron transition that converts part of the light energy into heat energy. This causes the light to decay. Based on the thickness of the artificial cornea and contact lens, the actual thickness of the hydrogel $(4.4 \mathrm{~mm})$ was corrected to the light transmittance.

IPN hydrogels formed for $24 \mathrm{~h}$ and the transmissivity reached more than $97 \%$. This is more than national standard. The unstinted soft contact lens transmission ratio is greater than $92 \%$ [42]. The transmittance of pure silk hydrogel is only about $21 \%$ (Figure $4 \mathrm{~A}, \mathrm{~B}$ ). IPN hydrogel showed good light transmission properties. The results indicate that the structure of the hydrogel material chain is interpenetrating network structure and the pure silk hydrogel substantially crystalline structure. This hinders the light pass through, so the light transmittance is low. IPN hydrogels still retain good light transmission over time. The light transmission remains as high as $80 \%$ over a week. This is mainly due to the high degree of entanglement of the molecular chains endow the hydrogel stable internal non-crystalline structure. This insures its excellent light transmission properties.

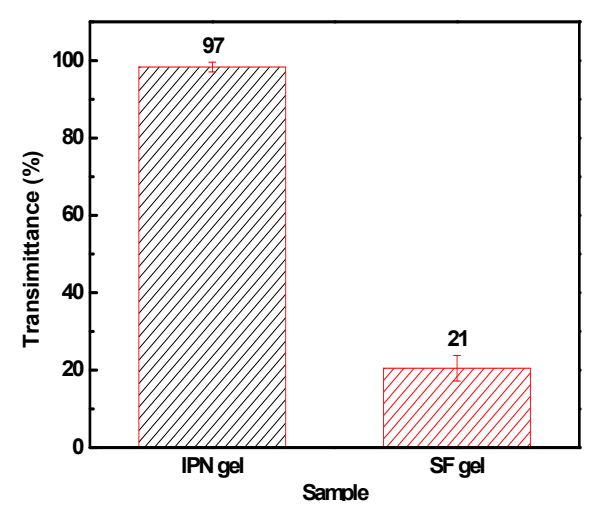

(A)

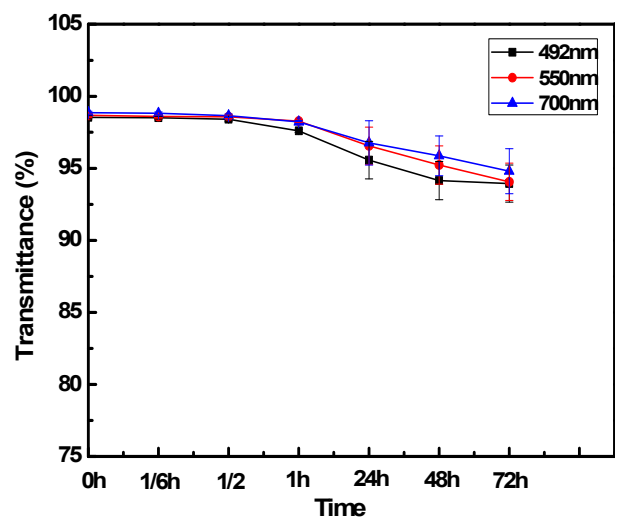

(B)

Figure 4. Light transmittance (A) at $550 \mathrm{~nm}$. (B) IPN hydrogel transmittance at different times; The solid content of IPN hydrogel was $10 \mathrm{~g} / \mathrm{L}$, SF:NVP was 8:2 and the thickness of material was $4.4 \mathrm{~mm}$. 


\subsection{Enzymatic Degradation of Hydrogels In Vitro}

Interpenetrating network structure in the loss of a macromolecule, the degree of crosslinking decreased rapidly dissolved in water. The rate of degradation of the hydrogel was up to over $80 \%$ in $24 \mathrm{~h}$, whereas pure silk fibroin hydrogel was degraded only about $40 \%$ (Figure 5 ). The main reason might be due to the enzymatic action, the silk fibroin in the IPN gel was degraded. This resulted in a decrease in the degree of crosslinking of the gel and rapid degradation. Thus, the IPN gel was a cross-linked network of hydrogels formed by intertwining and cross-linking of silk fibroin molecules and PVP molecules.

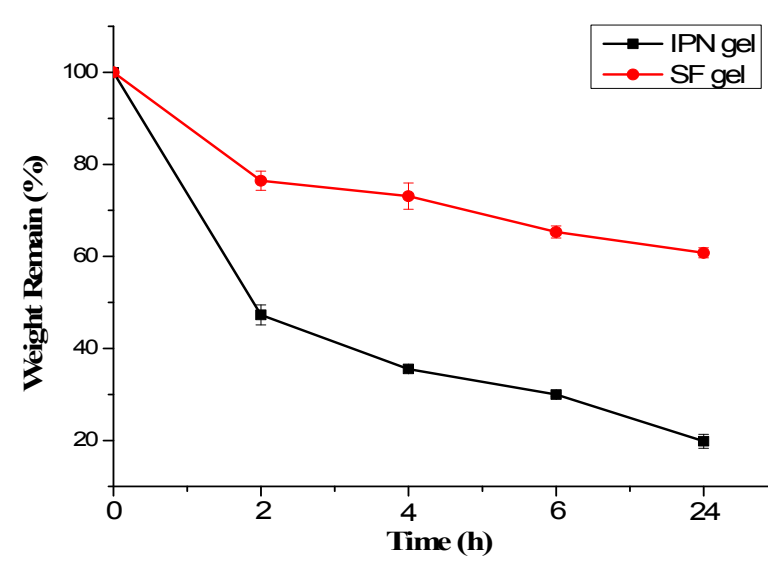

Figure 5. Degradation of silk fibroin hydrogels. In $2 \mathrm{U} / \mathrm{mL}$ protease XIV PBS solution $\left(37^{\circ} \mathrm{C}\right.$, pH: 7.4). The solid content of SF hydrogel was $10 \mathrm{~g} / \mathrm{L}, \mathrm{SF}: \mathrm{NVP}$ was 8:2 and the thickness of material was $4.4 \mathrm{~mm}$.

\section{Discussion}

Reports over the past decades have stated that silk hydrogel was prepared by ultrasonic induction, temperature, $\mathrm{pH}$ or crosslinking agent [21,43-45]. The silk hydrogel prepared by these methods, which exhibit a weak resilience and low light transmission, because of $\beta$-sheet structure. Meanwhile the toxicity of chemical crosslinking agents was present, which may limit its practical use. To improve the resilience and light transmission as well as the biosecurity, we prepared PVP-SF IPN hydrogel using $\mathrm{HRP}-\mathrm{H}_{2} \mathrm{O}_{2}$ systems.

As shown in Scheme 2, the SF molecules form a loose globular structure in the solution with random coil structure. When NVP added into SF solution, the small NVP molecules disperse in water and in loose globular formed by SF macromolecules. When PVP macromolecules synthesized by the free radical polymerization of NVP in $\mathrm{HRP}-\mathrm{H}_{2} \mathrm{O}_{2}$ systems, the polymerization occurs in the solvent (water), as well the interface of SF macromolecules and water. Then the crosslinking points of physical entanglement are formed by segments of SF macromolecules and segments of PVP macromolecules, which can be called interpenetrating network. When the crosslinking density rises to the critical value, the viscosity of the solution rises to infinity and the IPN hydrogel is formed. The movement of silk fibroin chain is limited due to the existence of physical crosslinking. Thus, the silk fibroin chain segment is difficult to rotate freely to form a stable $\beta$-sheet structure. That is why the structure of SF in IPN hydrogel is mainly random coil, while the structure of pure SF hydrogel is mainly $\beta$-sheet (Figure 2A).

The formation of larger particles or silk II crystals, which may make hydrogel opaque, is also limited by the interpenetrating network structure formed by SF and PVP. That is the reason why PVP-SF IPN hydrogel has good transparency and can remain for a long time. The transmittance of PVP-SF IPN hydrogel (8:2) is $97 \%$ significantly higher than that of pure silk fibroin hydrogel (21\%) (Figure 3).

When PVP-SF IPN hydrogel was immersed into protease XIV PBS solution, the chain of SF molecular was cut into small pieces by the enzyme while the chain of PVP will not be cut and still keep long chain. However, due to SF molecular was cut from long chain to small fragments, the crosslinking point of physical entanglement will be destroyed. And then the interpenetrating network structure was 
break up. The PVP and small fragments of SF was dissolved in water. The degradation process is very fast due to the structure of SF is random coil but not $\beta$-sheet and It is no need to completely degrade SF molecular while only need cut the point of physical entanglement. That is why the degradation rate of PVP-SF IPN hydrogel is so far faster than that of pure silk hydrogel (Figure 5).

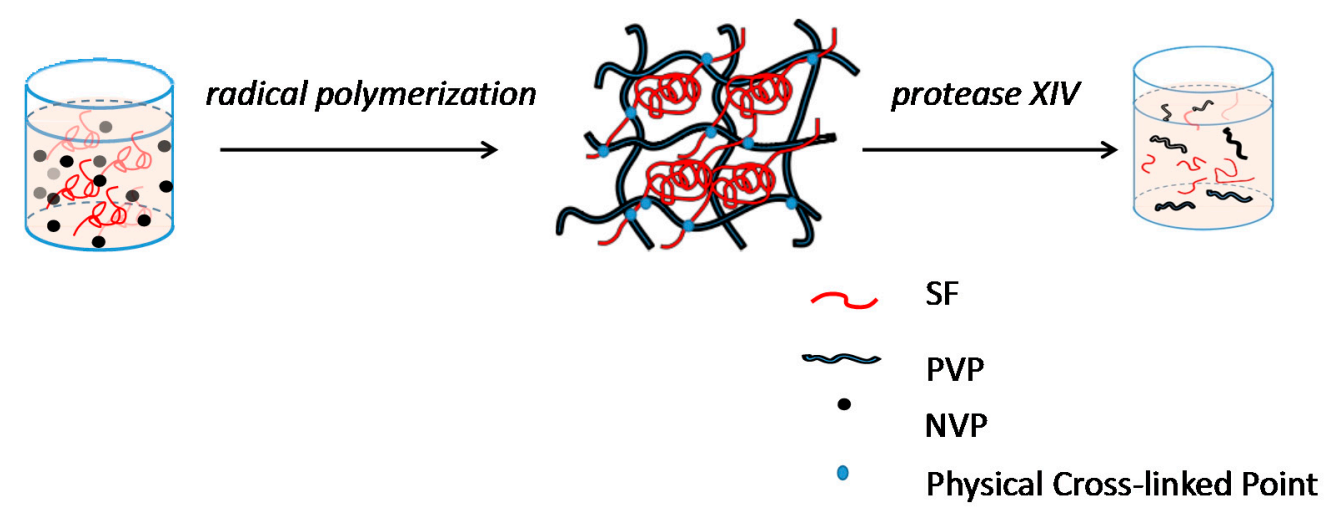

Scheme 2. Formation and degradation of PVP-SF IPN hydrogel.

In summary, the PVP-SF IPN hydrogels fabricated are superior to the pure silk fibroin hydrogel in terms of mechanical properties, light transmittance and biodegradability due to the mutual network structure.

\section{Conclusions}

We prepared a series of PVP-SF IPN hydrogels with high desirable and tunable features for biomedical applications. The PVP-SF IPN hydrogels have an excellent translucency $(97 \%)$ degree, higher transmittance, higher compressive strength and compressive resilience and rapid protease degradation as compared to pure SF hydrogels. We also demonstrated that, by varying the concentration of silk fibroin in the IPN hydrogel, the structural, pore size and Compression mechanical properties of the resulting IPN hydrogels could be tuned. It is expected that this type of hydrogel can be used in cell migration investigation and also where transparency films are needed as biomedical materials.

Acknowledgments: This work was supported by The National Key Research and Development Program of China (Grant No. 2017YFC1103602), National Natural Science Foundation of China (Grant No. 51373114, 51741301), PAPD and Nature Science Foundation of Jiangsu, China (Grant No. BK20171239, BK20151242).

Author Contributions: Shenzhou Lu, Zhuping Yin and Tieling Xing conceived and designed the experiments; Tian Zhu, Dajiang Kuang and Feng Wu performed the experiments and analyzed the data; Dajiang Kuang, Subhas C. Kundu and Feng Wu wrote the paper. All authors discussed the results and improved the final text of the paper.

Conflicts of Interest: The authors declare no conflict of interest.

\section{References}

1. Hamidi, M.; Azadi, A.; Rafiei, P. Hydrogel nanoparticles in drug delivery. Adv. Drug Deliv. Rev. 2008, 60, 1638-1649. [CrossRef] [PubMed]

2. Numata, K.; Katashima, T.; Sakai, T. State of water, molecular structure and cytotoxicity of silk hydrogels. Biomacromolecules 2011, 12, 2137-2144. [CrossRef] [PubMed]

3. Peppas, N.A.; Bures, P.; Leobandung, W.; Ichikawa, H. Hydrogels in pharmaceutical formulations. Eur. J. Pharm. Biopharm. 2000, 50, 27-46. [CrossRef]

4. Tomme, S.R.V.; Storm, G.; Hennink, W.E. In situ gelling hydrogels for pharmaceutical and biomedical applications. Int. J. Pharm. 2008, 355, 1-18. [CrossRef] [PubMed] 
5. Kim, J.; Kim, I.S.; Cho, T.H.; Lee, K.B.; Hwang, S.J.; Tae, G.; Sun, K. Bone regeneration using hyaluronic acid-based hydrogel with bone morphogenic protein-2 and human mesenchymal stem cells. Biomaterials 2007, 28, 1830-1837. [CrossRef] [PubMed]

6. Peppas, N.A.; Hilt, J.Z.; Khademhosseini, A.; Langer, R. Hydrogels in biology and medicine: From molecular principles to bionanotechnology. Adv. Mater. 2006, 18, 1345-1360. [CrossRef]

7. Kundu, B.; Kurland, N.E.; Bano, S.; Patra, C.; Engel, F.B.; Yadavalli, V.K.; Kundu, S.C. Silk proteins for biomedical applications: Bioengineering perspectives. Prog. Polym. Sci. 2014, 39, 251-267. [CrossRef]

8. Rajkhowa, R.; Levin, B.; Redmond, S.L.; Li, L.H.; Wang, L.; Kanwar, J.R.; Atals, M.D.; Wang, X. Structure and properties of biomedical films prepared from aqueous and acidic silk fibroin solutions. J. Biomed. Mater. Res. Part A 2011, 97, 37-45. [CrossRef] [PubMed]

9. Zhao, H.; Heusler, E.; Jones, G.; Li, L.; Werner, V.; Germershaus, O.; Meinel, L. Decoration of silk fibroin by click chemistry for biomedical application. J. Struct. Biol. 2014, 186, 420-430. [CrossRef] [PubMed]

10. Kundu, S.C.; Kundu, B.; Talukdar, S.; Bano, S.; Nayak, S.; Kundu, J.; Mandal, B.B.; Bhardwaj, N.; Botlagunta, M.; Dash, B.C.; et al. Nonmulberry silk biopolymers. Biopolymers 2012, 97, 455-467. [CrossRef] [PubMed]

11. Yannas, I.V.; Lee, E.; Orgill, D.P.; Skrabut, E.M.; Murphy, G.F. Synthesis and characterization of a model extracellular matrix that induces partial regeneration of adult mammalian skin. Proc. Natl. Acad. Sci. USA 1989, 86, 933-937. [CrossRef] [PubMed]

12. Wichterle, O.; Lim, D. Hydrophilic gels for biological use. Nature 1960, 185, 117-118. [CrossRef]

13. Lawrence, B.D.; Marchant, J.K.; Pindrus, M.A.; Omenetto, F.G.; Kaplan, D.L. Silk film biomaterials for cornea tissue engineering. Biomaterials 2009, 30, 1299-1308. [CrossRef] [PubMed]

14. Vepari, C.; Kaplan, D.L. Silk as a biomaterial. Prog. Polym. Sci. 2007, 32, 991-1007. [CrossRef] [PubMed]

15. Rockwood, D.N.; Preda, R.C.; Yücel, T.; Wang, X.; Lovett, M.L.; Kaplan, D.L. Materials fabrication from Bombyx mori silk fibroin. Nat. Protoc. 2011, 6, 1612-1631. [CrossRef] [PubMed]

16. Li, C.; Vepari, C.; Jin, H.J.; Kim, H.J.; Kaplan, D.L. Electrospun silk-BMP-2 scaffolds for bone tissue engineering. Biomaterials 2006, 27, 3115-3124. [CrossRef] [PubMed]

17. Tsioris, K.; Raja, W.K.; Pritchard, E.M.; Panilaitis, B.; Kaplan, D.L.; Omenetto, F.G. Fabrication of Silk Microneedles for Controlled Release Drug Delivery. Adv. Funct. Mater. 2012, 22, 330-335. [CrossRef]

18. Yin, Z.; Kuang, D.; Wang, S.; Zheng, Z.; Yadavalli, V.K.; Lu, S. Swellable silk fibroin microneedles for transdermal drug delivery. Int. J. Biol. Macromol. 2018, 106, 48-56. [CrossRef] [PubMed]

19. Kim, U.J.; Park, J.; Li, C.; Jin, H.J.; Valluzzi, R.; Kaplan, D.L. Structure and properties of silk hydrogels. Biomacromolecules 2004, 5, 786-792. [CrossRef] [PubMed]

20. Hu, X.; Lu, Q.; Sun, L. Biomaterials from Ultrasonication induced Silk Fibroin-Hyaluronic Acid Hdrogel. Biomacromolecules 2010, 11, 3178-3188. [CrossRef] [PubMed]

21. Gil, E.S.; Frankowski, D.J.; Spontak, R.J.; Hudson, S.M. Swelling behavior and morphological evolution of mixed gelatin/silk fibroin hydrogels. Biomacromolecules 2005, 6, 3079-3087. [CrossRef] [PubMed]

22. Ming, J.; Zuo, B. A novel silk fibroin/sodium alginate hybrid scaffolds. Polym. Eng. Sci. 2014, 54, $129-136$. [CrossRef]

23. Hayes, T.G.; Hume, R.M.; Kredovski, K.C. Interpenetrating Polymer Network. U.S. Patent 5997574 A, 7 December 1999.

24. Myung, D.; Koh, W.; Ko, J.; Hu, Y.; Carrasco, M.; Noolandi, J.; Ta, C.N.; Frank, C.W. Biomimetic strain hardening in interpenetrating polymer network hydrogels. Polymer 2007, 48, 5376-5387. [CrossRef]

25. Gudeman, L.F.; Peppas, N.A. Preparation and characterization of $\mathrm{pH}$-sensitive, interpenetrating networks of poly (vinyl alcohol) and poly (acrylic acid). J. Appl. Polym. Sci. 1995, 55, 919-928. [CrossRef]

26. Bertoluzza, A.; Monti, P.; Garcia-Ramos, J.V.; Simoni, R.; Caramazza, R.; Calzavara, A. Applications of Raman spectroscopy to the ophthalmological field: Raman spectra of soft contact lenses made of poly-2-hydroxyethylmethacrylate (PHEMA). J. Mol. Struct. 1986, 143, 469-472. [CrossRef]

27. Wajs, G.; Lenne, W. Method for Preparing a Crosslinked Graft Copolymer of Silicone and Polyvinylpyrrolidone for Use as a Contact Lens and a Contact Lens Produced Thereby. U.S. Patent US3959102, 25 May 1976.

28. Kunitomo, T.; Kenjo, H.; Nagaoka, S.; Yoshioka, T.; Tanzawa, H. Cross-Linked n-Vinyl Pyrrolidone Polymer Composition Suitable for Contact Lenses. U.S. Patent 3,949,021A, 6 April 1976. 
29. Hosaka, S.; Uchida, T. Method of Assaying the Metabolic Activity of Cells Capable of Endocytosis. U.S. Patent US4788142A, 29 November 1988.

30. Kitano, S.; Koyama, Y.; Kataoka, K.; Okano, T.; Sakurai, Y. A novel drug delivery system utilizing a glucose responsive polymer complex between poly (vinyl alcohol) and poly ( $N$-vinyl-2-pyrrolidone) with a phenylboronic acid moiety. J. Control. Release 1992, 19, 161-170. [CrossRef]

31. Benahmed, A.; Ranger, M.; Leroux, J.C. Novel polymeric micelles based on the amphiphilic diblock copolymer poly(N-vinyl-2-pyrrolidone)-block-poly(D,L-lactide). Pharm. Res. 2001, 18, 323-328. [CrossRef] [PubMed]

32. Quinn, F.X.; Kampff, E.; Smyth, G.; McBrierty, V.J. Water in hydrogels. 1. A study of water in poly (N-vinyl-2-pyrrolidone/methyl methacrylate) copolymer. Macromolecules 1988, 21, 3191-3198. [CrossRef]

33. Lai, Y.C. Effect of crosslinkers on photocopolymerization of $N$-vinylpyrrolidoneand methacrylates to give hydrogels. J. Appl. Polym. Sci. 1997, 66, 1475-1484. [CrossRef]

34. Li, C.; Luo, T.; Zheng, Z.; Murphy, A.R.; Wang, X.; Kaplan, D.L. Curcumin-functionalized silk materials for enhancing adipogenic differentiation of bone marrow-derived human mesenchymal stem cells. Acta Biomater. 2015, 11, 222-232. [CrossRef] [PubMed]

35. Silva, S.S.; Popa, E.G.; Gomes, M.E.; Oliveira, M.B.; Nayak, S.; Subia, B.; Mano, J.F.; Kundu, S.C.; Reis, R.L. Silk hydrogels from non-mulberry and mulberry silkworm cocoons processed with ionic liquids. Acta Biomater. 2013, 9, 8972-8982. [CrossRef] [PubMed]

36. Dain, S.J.; Pye, D.C.; Bogaert, N.; Cooper, S.J.; Klaunxer, P.M.; Nicolson, A. Transmittance characteristics of tinted hydrogel contact lenses intended to change iris colour. Clin. Exp. Optom. 1993, 76, 74-79. [CrossRef]

37. Pons, M.; Fiszman, S.M. Instrumental texture profile analysis with particular reference to gelled systems. J. Texture Stud. 1996, 27, 597-624. [CrossRef]

38. Ming, J.; Li, M.; Han, Y.; Chen, Y.; Li, H.; Zuo, B.; Pan, F. Novel two-step method to form silk fibroin fibrous hydrogel. Mater. Sci. Eng. C 2016, 59, 185-192. [CrossRef] [PubMed]

39. Liu, Y.; Ling, S.; Wang, S.; Chen, X.; Shao, Z. Thixotropic silk nanofibril-based hydrogel with extracellular matrix-like structure. Biomater Sci. 2014, 2, 1338-1342. [CrossRef]

40. Li, X.M.; Cui, Y.D.; Cai, L.B. Study on copolymer hydrogel for contact lens. Polym. Mater. Sci. Eng. 2004, 20, 191-194.

41. Sassaroli, A.; Fantini, S. Comment on the modified Beer-Lambert law for scattering media. Phys. Med. Biol. 2004, 49, N255-N257. [CrossRef] [PubMed]

42. Jeng, B.H.; Halfpenny, C.P.; Meisler, D.M.; Stock, E.L. Management of focal limbal stem cell deficiency associated with soft contact lens wear. Cornea 2011, 30, 18-23. [CrossRef] [PubMed]

43. Lu, S.; Liu, M.; Ni, B.; Gao, C. A novel pH and thermo sensitive PVP/CMC semi IPN hydrogel: Swelling, phase behavior and drug release study. J. Polym. Sci. Part B Polym. Phys. 2010, 48, 1749-1756. [CrossRef]

44. Wang, X.; Kluge, J.A.; Leisk, G.G.; Kaplan, D.L. Sonication-induced gelation of silk fibroin for cell encapsulation. Biomaterials 2008, 29, 1054-1064. [CrossRef] [PubMed]

45. Nguyen, D.H.; Tran, N.Q.; Nguyen, C.K. Tetronic-grafted chitosan hydrogel as an injectable and biocompatible scaffold for biomedical applications. J. Biomater. Sci. Polym. Ed. 2013, 24, 1636-1648. [CrossRef] [PubMed]

(c) 2018 by the authors. Licensee MDPI, Basel, Switzerland. This article is an open access article distributed under the terms and conditions of the Creative Commons Attribution (CC BY) license (http://creativecommons.org/licenses/by/4.0/). 